\title{
Pattern of Eye Diseases in Ophthalmic Outpatient Clinic of Al-Zahraa University Hospital: An Observational Descriptive Study \\ ${ }^{1}$ Afaf Hassan Rashwan, ${ }^{2}$ Omaima I. Abo-Elkheir, ${ }^{3}$ Aya Alsayed I. Metwally
}

Departments of ${ }^{1}$ Ophthalmology and ${ }^{2}$ Community and Occupational Medicine, Faculty of Medicine (for Girls), Al-Azhar University, Cairo, Egypt, ${ }^{3}$ Department of Ophthalmology, 15 May Hospital, Helwan, Egypt Corresponding author: Aya Alsayed I. Metwally. Email: dr.ayametwally@gmail.com

\begin{abstract}
Background: A study of the pattern of the eye diseases is very essential because while some eye conditions are only causing of ocular morbidity, others invariably lead to blindness. However, some conditions are curable, others are largely preventable. Objective: The aim of this study was to determine the pattern of different eye diseases among patients attending the Ophthalmic Outpatient Clinic of Al-Zahraa University Hospital.

Subjects and methods: This study was carried out on 500 patients recruited from the Outpatient Clinic of the Ophthalmology Department, AL-Zahraa University Hospital. The study was performed from December 2018 to August 2019. All participants were subjected to fulfilling a pre designed questionnaire including questions about demographic data, a detailed ophthalmological history and a complete Ophthalmological Examination.

Results: Retinal diseases (20.2\%) were the most common eye diseases among the studied group followed by errors of refraction (19.6\%), cataract (19.4\%), dry eye (12.8\%) and intravitreal injection (6.4\%). There was a significant difference between male and female population regarding ocular trauma and different eye diseases. Also, there was a significant difference between occupation groups regarding diagnosis of different eye diseases and between age groups regarding diagnosis of different eye diseases. Conclusion: It could be concluded that due to the presence of a variety of ocular disorders that affect different anatomical parts of the eye, routine clinical examination and screening programs to decrease the incidence and prevalence of ocular morbidity are required.
\end{abstract}

Keywords: Pattern of eye diseases, ophthalmology clinic, Cairo, Al-Azhar University, Egypt.

\section{INTRODUCTION}

A study of the pattern of the eye diseases is very essential because while some eye conditions are only causing of ocular morbidity, others invariably lead to blindness. However, some conditions such as refractive errors and cataract are curable, others like measles and vitamin A deficiency are largely preventable [1]. Prevalence of eye diseases vary in different communities according to several factors, which include social and environmental characters of the community, health habits of the community, personnel hygiene and technical procedures used in the diagnosis of eye diseases ${ }^{[2]},{ }^{[3]}$.

Trachoma is still the chief cause of infectious blindness in the world ${ }^{[4]}$. Visual impairment and blindness remain a major problem in the world nowadays. There are an estimated 161 million suffering from visual disability and 37 million people worldwide suffering from blindness; around $80 \%$ of these are preventable. Cataract, which can be simply operated upon and cured, is responsible for more than half of the blindness in the world. Glaucoma, diabetic retinopathy, trachoma, uncorrected refractive error and childhood blindness make up the rest ${ }^{[4]}$. Globally, cataract is considered the principal cause of blindness. Smoking, diabetes, and exposure to UVB light have been recognized as risk factors for cataract development ${ }^{[5]}$. Deficient protective measures in workplaces appear to be the main cause of ocular injury, especially in young males. It can be assumed that health education, as well as application of safety measures and protocols, will significantly reduce the incidence of ocular injuries in the target population ${ }^{[6]}$. Diabetic retinopathy (DR) was $20.5 \%$ among Egyptian diabetic patients who were above 18 years of age; where $82 \%$ of patients were unaware of the dangers of diabetes on the eyes ${ }^{[7]}$. Hypertension is considered also a major risk factor for the development of hypertensive retinopathy and other retinal vascular diseases, such as retinal vein and artery occlusion, and ischemic optic neuropathy. Moreover, high blood pressure increases the risk of both development of diabetic retinopathy and its progression. The etiology and disease mechanisms of both diabetes and hypertension are overlapped. They share many common risk factors e.g. dyslipidemia, proteinuria ${ }^{[8]}$. Early diagnosis and treatment can prevent all diabetic ocular complications. However, the cornerstone for prevention of these complications are through Good control of blood glucose and other systemic risk factors such as hypertension and hyperlipidemia [9]. A clear awareness of the pattern of eye diseases will form a framework which will utilize to effectively prevent or treat diseases that may cause blindness. This in turn will decrease needless blindness and visual impairment, and eventually, it will help to get their full potential in life ${ }^{[10]}$. This type of study is helpful to get an idea about the epidemiology of any ocular disorder. It is necessary to organize community education and ensure early treatment to reduce the prevalence of these diseases in the general population ${ }^{[11]}$.

The aim of this work was to determine the pattern of different eye diseases among patients attending the ophthalmic outpatient clinic of Al-Zahraa University Hospital.

\section{SUBJECTS AND METHODS}

This observational Descriptive Cross-Sectional study included a total of 500 patients attending at 
Outpatient Clinic of the Ophthalmology Department, AL-Zahraa University Hospital. This study was conducted between December 2018 to August 2019.

\section{Ethical consideration:}

The study was approved by the Ethical Committee at the Faculty of Medicine for Girls, Al -Azhar

University. At the beginning of the interview, an informed oral consent was obtained from participants after explanation of the purpose of the study and before participation in the study. Complete confidentiality was ensured for all patients. The patient had the right to refuse to participate without affection of the care given to him/her.

\section{All participants were subjected to:}

A. Fulfilling a predesigned questionnaire including questions about demographic data including (age, gender, occupation, residence, marital status).

B. Detailed ophthalmological history including ocular past history, any systemic diseases especially diabetes mellitus and hypertension and the ocular complaints and its onset, duration.

C. Ocular examination:

1. Meticulous examination was done to the patients: -

- Simple eye examination by torch, testing for strabismus.

- Auto refraction, visual acuity testing.

- Fundus examination.

2. Both eyes were examined with a slit lamp

3. The intraocular pressure was measured by the applanation tonometer.

\section{Statistical design:}

The collected data were coded, fed to the computer and organized.

-Statistical analysis was done by using Statistical Package for Social Science (SPSS) program version 25.

-Descriptive statistics: data were presented by numbers and Percentages.

-A significance (Chi-square) test was used for comparison between the studied groups.

-The level of significance was taken at p-value $<0.05$.

-Results were presented in tables and figures.

\section{RESULTS}

A total number of 500 participants were included in this study from the outpatient clinic of the Ophthalmology Department at Al-Zahraa University Hospital.

In this study the pattern of eye disease varied according to the gender, different age group and occupation. It was higher in females (51.2\%) than males $(48.8 \%)$ and representing the highest percentage at the age group 40-59 years (32.6\%). The highest reported disorder among the studied group was retinal diseases $(21.6 \%)$, mainly among those aged $40-60$ years $(37.4 \%)$.
Proliferative Diabetic retinopathy was the highest type $(12.6 \%)$ followed by Non proliferative diabetic retinopathy $(6.8 \%)$.

There were $19.6 \%$ of the studied cases having errors of refractions mainly among teenagers $54.2 \%$ of those aged $\leq 18$ years and $29.0 \%$ of those aged 19-39 years old. Myopia was the highest type (46\%) followed by Astigmatism (39\%) and hyperopia (15\%). Lens diseases were reported among $17 \%$ of the studied group; mainly among those aged 60 years and above (53.4\%). Eye lid diseases reported among $12.8 \%$ of the studied group mainly among those aged 19-39 years old $(23.2 \%)$. Meibomian gland dysfunction was the highest reported type $(25.7 \%)$.

There were $(12.4 \%)$ of the studied group having Conjunctival diseases mainly (28.9\%) among teenagers (those aged $\leq 18$ years). MPC \& Trachoma were the highest recorded type (16.0\%) followed by allergic conjunctivitis (15.4\%); both were higher among males. Regarding Trauma, there was $6 \%$ of the studied group reported having trauma; mainly among manual workers $(25 \%)$ and drivers (13.3\%).

Figure1 and 2 show the age and gender distribution among the studied group. There were $51.2 \%$ females versus $48.8 \%$ males, where $(32.6 \%)$ were in the age group from $40-59$ years, and $(27.6 \%)$ were in the age group of 19-39 years.

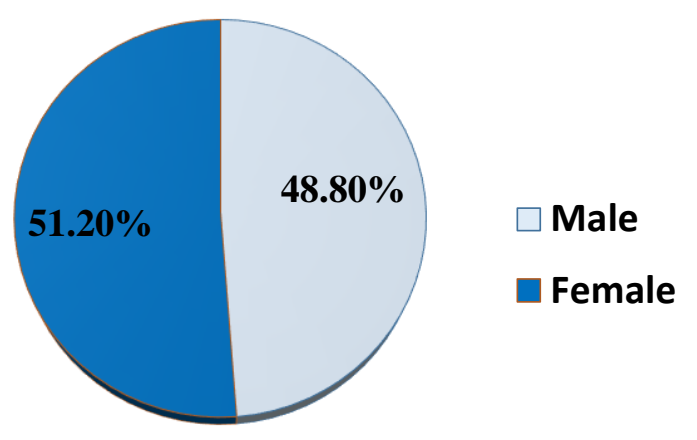

Figure 1: Gender distribution among the studied group.

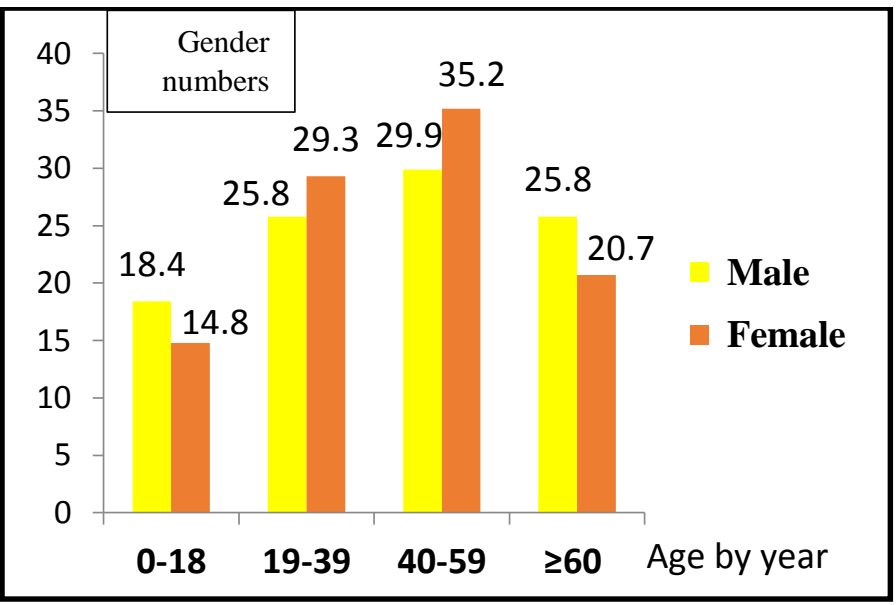

Figure 2: The age and gender distribution of patients. 


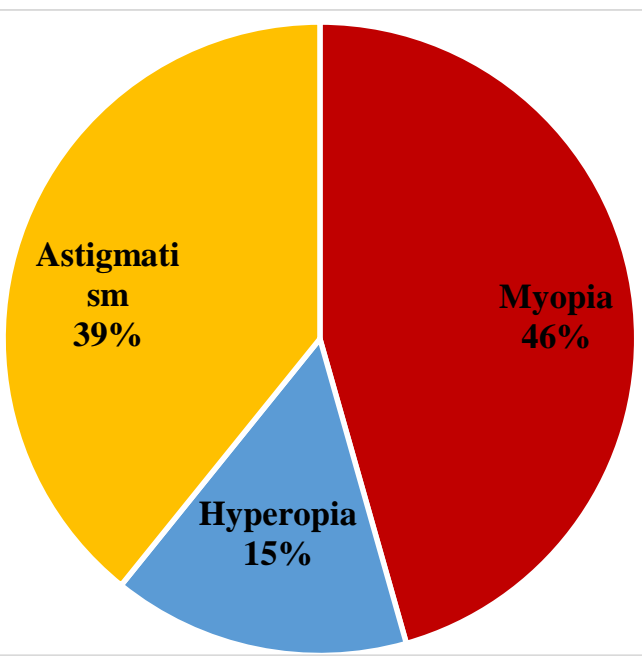

Figure 3: Showed the percentage of myopia, hyperopia and astigmatism

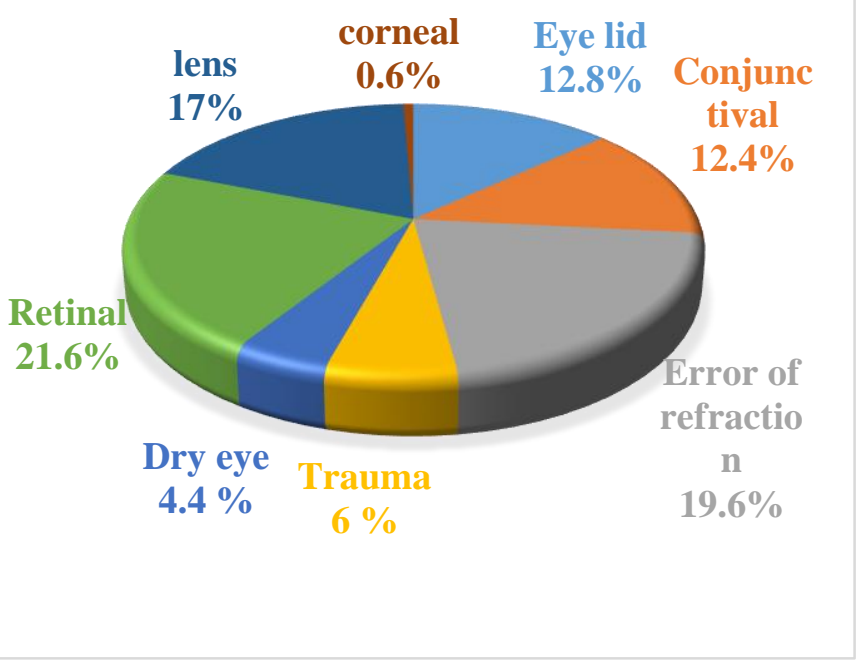

Figure 4: This figure showed the percentage of different eye diseases among the studied group

Table 1: Eye lid diseases, conjunctival manifestations, corneal affections among the studied group by gender

\begin{tabular}{|c|c|c|c|c|c|}
\hline \multirow{3}{*}{ Items } & Male & Female & Total & \multirow{3}{*}{$\mathbf{X}^{2}$} & \multirow{3}{*}{ p-value } \\
\hline & $\mathrm{N}=244$ & $\mathrm{~N}=256$ & $\mathrm{~N}=\mathbf{5 0 0}$ & & \\
\hline & $(\%)$ & $(\%)$ & $(\%)$ & & \\
\hline \multicolumn{6}{|l|}{ Eye lid examination } \\
\hline Normal & 25.1 & 25.9 & 50.9 & \multirow{5}{*}{.009} & \multirow{5}{*}{0.002} \\
\hline $\begin{array}{l}\text { Meibomian gland } \\
\text { dysfunction }\end{array}$ & 12 & 13.6 & 25.7 & & \\
\hline Scaly blepharitis & 2.2 & 5.8 & 8 & & \\
\hline Chalazion \&Stye & 4.8 & 2.4 & 7.2 & & \\
\hline *Other lid disorders & 5.4 & 3.8 & 8.2 & & \\
\hline \multicolumn{6}{|l|}{ Conjunctival conditions } \\
\hline Normal & 60.2 & 67.6 & 64.0 & \multirow{6}{*}{0.079} & \multirow{6}{*}{0.052} \\
\hline MPC\&Trachoma & 16.4 & 15.6 & 16.0 & & \\
\hline Allergic conjunctivitis & 16.0 & 14.8 & 15.4 & & \\
\hline Pterygium & 2.9 & 0.8 & 1.8 & & \\
\hline $\begin{array}{l}\text { Subconjunctival } \\
\text { haemorrhage }\end{array}$ & 4.5 & 0.8 & 2.6 & & \\
\hline Bitots spot & 0.0 & 0.4 & 0.2 & & \\
\hline \multicolumn{6}{|l|}{ Corneal conditions } \\
\hline Normal & 87.7 & 90.2 & 89.0 & \multirow{6}{*}{0.026} & \multirow{6}{*}{0.008} \\
\hline Punctate keratitis & 5.3 & 7.4 & 6.4 & & \\
\hline Ulcer & 3.3 & 0.8 & 2.0 & & \\
\hline Corneal abrasions & 0.8 & 1.6 & 1.2 & & \\
\hline Opacity & 2.0 & 0.0 & 1.0 & & \\
\hline Kerato precipitates & 0.8 & 0.0 & 0.4 & & \\
\hline
\end{tabular}


Table 2: Conditions related to pupil, anterior chamber, iris and lens among the studied group by gender

\begin{tabular}{|c|c|c|c|c|c|}
\hline \multirow{3}{*}{ Items } & Male & Female & Total & \multirow{3}{*}{$\mathbf{X}^{2}$} & \multirow{3}{*}{ p-value } \\
\hline & $\mathrm{N}=\mathbf{2 4 4}$ & $\mathrm{N}=256$ & $\mathrm{~N}=500$ & & \\
\hline & $(\%)$ & $(\%)$ & $(\%)$ & & \\
\hline \multicolumn{6}{|l|}{ Pupil conditions } \\
\hline Normal & 91.0 & 94.9 & 93 & \multirow[t]{4}{*}{0.246} & \multirow[t]{4}{*}{0.177} \\
\hline RAPD & 8.2 & 5.1 & 6.6 & & \\
\hline Sphincter tear & 0.4 & 0.0 & 0.2 & & \\
\hline Traumatic mydriasis & 0.4 & 0.0 & 0.2 & & \\
\hline \multicolumn{6}{|l|}{ Anterior champers } \\
\hline Normal & 96.3 & 99.6 & 98 & \multirow{3}{*}{0.031} & \multirow{3}{*}{0.017} \\
\hline Flare and cells & 3.3 & 0.4 & 1.8 & & \\
\hline Shallow & 0.4 & 0.0 & 0.2 & & \\
\hline \multicolumn{6}{|l|}{ Iris } \\
\hline Normal & 90.2 & 89.8 & 90 & \multirow{7}{*}{0.611} & \multirow{7}{*}{0.494} \\
\hline Iridocyclitis & 1.6 & 0.4 & 1.0 & & \\
\hline Rubiosis iridis & 7.0 & 8.2 & 7.6 & & \\
\hline $\begin{array}{l}\text { Persistent pupillary } \\
\text { membrane }\end{array}$ & 0.4 & 0.4 & 0.4 & & \\
\hline Leucoma adherent & 0.4 & 0.8 & 0.6 & & \\
\hline Iridodenisis & 0.4 & 0.4 & 0.2 & & \\
\hline Traumatic iritis & 0.4 & 0.0 & 0.2 & & \\
\hline \multicolumn{6}{|l|}{ Lens } \\
\hline Normal & 70.1 & 77.7 & 74 & \multirow{6}{*}{0.242} & \multirow{6}{*}{0.202} \\
\hline Lens dislocation & 0.8 & 0.4 & 0.6 & & \\
\hline Lens sublaxation & 1.6 & 0.4 & 1.0 & & \\
\hline Aphakic & 0.4 & 0.0 & 0.2 & & \\
\hline Pseudophakic & 6.1 & 3.5 & 4.8 & & \\
\hline Cataractous lens & 20.9 & 18.0 & 19.4 & & \\
\hline
\end{tabular}

\section{DISCUSSION}

Vision is an essential requirement for learning and communication. Further, optimal vision is important for learning, health and educational requirements ${ }^{[12] .}$

In the present study the majority of participants were females $(51.2 \%)$ where males represented $(48.8 \%)$. This could be due to most of them were housewives (36\% of the female group), where they can attend the clinic at any time without commitment to work.

In a similar study carried out in Ghana, the majority of participants were also females $(61.8 \%)$ while $(38.2 \%)$ were males ${ }^{[13]}$.

In this study retinal diseases were the most common eye disorder seen (20.2\%). Diabetic retinopathy represented $19.2 \%$ of them $12.6 \%$ had PDR and $6.8 \%$ had Non-PDR. This high percentage of DR was related to the fact that $26 \%$ of the studied group had DM and $20.2 \%$ of them had HTN. Also, it could be explained by lack of awareness about the importance of regular eye exam for diabetic patients so presented to the clinic with more advanced complications such as the PDR.

In accordance with these results a study done in Egypt showed that diabetic retinopathy represents $27 \%$.this is relatively high and could be explained by the high level of obesity, bad dietary habits and low level of education ${ }^{[8]}$.

Results of the present study revealed that Errors of refraction were the second most common eye disease (19.6\%). Mainly (54.2\%) among teenagers (those aged $\leq 18$ years) and $29.0 \%$ among those aged 19-39 years old.

Similar results of a study carried out in Southwestern Nigeria which reported that refractive error representing $19.5 \%{ }^{[14]}$. While a study conducted in Ghana, revealed that refractive error representing 26.30 $\%$ [15].

However, another study conducted in Ghana revealed that uncorrected refractive errors were the fourth commonest cause of ocular morbidity with a 
prevalence of $8.90 \%$. The low prevalence in this study could be due to ignorance as some patients fail to complain of poor vision to eye care providers because of negative perception about spectacle wear and the cost involved in getting one ${ }^{[13]}$.

While, hyperopia was the commonest refractive error in a private optometry practice in Nigeria, Bagaiya and Pam states ${ }^{[16]}$.

In this study, we found that cataract was the third most common eye disease (16.8\%) among the studied group, mostly among the retired persons $(23.2 \%)$ and those of aged above 60 (53.4\%).

In the same context results of previous studies revealed that cataract was $33.3 \%$ in southeastern Nigeria and in Saudi Arabia one of the most common causes of blindness was cataract, about $7 \%$ of all Saudi Arabians and $42 \%$ of those older than 40 years developed cataract [17], [18].

However, cataract was reported among $13.3 \%$ of cases from a semi-rural hospital in France ${ }^{[19]}$. Moreover a study carried out in China revealed that cataract was $35.0 \%{ }^{[20]}$. This higher incidence of cataract of the previous study in comparison to the present study may reflect environmental or genetic factors or may be due to difference in awareness and seeking medical advice.

In this study, we found that eye lid diseases were the fourth most common eye disease representing $(12.8 \%)$, the most common eye lid diseases were meibomian gland dysfunction represent $25.7 \%$ and the second most common one was scaly blepharitis (8\%), this relatively high percentage may be due to environmental factors, pollution, bad hygiene especially lack of face cleaning and also could be related to occupation such as drivers $(20.0 \%)$ and near workers $(42.1 \%)$. This is supported by the high percentage of lid diseases among near workers and drivers $48.7 \%, 20 \%$ respectively.

These results were in contrary with the results of a study carried out in Egypt revealed that lid diseases were the second most common ocular disorder, representing $27.4 \%$ of cases, where chalazia and blepharitis were more common among this category. This relatively high percentage of infectious eye lid diseases may be due to lack of proper hygiene and eye health education ${ }^{[21]}$.

Additionally, our study revealed that conjunctival diseases were $12.4 \%$ of which $16 \%$ was of MPC and $15.4 \%$ was of allergic conjunctivitis, with predominantly ( $28.9 \%$ ) of the age group below 18 years; this is more reasonable because conjunctival diseases are common in children.

On the contrary, a study carried out in the Southwestern Nigeria reported that infective conjunctivitis and allergic conjunctivitis were common reasons why patient presented at the eye $\operatorname{clinic}^{[22]}$
Additionally, in this study dry eye was reported among $4.4 \%$ of the studied group, this is relatively low prevalence and could be due to patient's negligence of their eye symptoms as well as lack of awareness about dry eye and its association with the different climate conditions.

Also, a study carried out in Egypt revealed that the dryness was the fourth most common presentation $(10 \%)^{[21] .}$

On the other hand, a study conducted in Jordan reported that dry eye was representing (49\%).This is a relatively high percentage in comparison to our study that could be related to increased awareness about the symptoms and hazards of dry eye as well as differences in climate conditions ${ }^{[23]}$.

Results of the present study revealed that eye trauma was reported among $6 \%$ of the studied group, of which the most common type was blunt trauma (4\%) followed by corneal and conjunctival foreign bodies and corneal abrasion $(2.2 \%)$.

In a similar study carried out in Egypt reported that ocular trauma represents $(6.8 \%)$ with the majority of trauma cases $80 \%$ being minor injuries (impacted corneal and conjunctival foreign bodies and unintentional blows to the eye $\mathrm{e}^{[21] \text {. }}$

On the contrary a study carried out in Uttrakhand reported that the magnitude of ocular trauma was found to be $1.03 \%$ out of total ocular patients seen in the outpatients department ${ }^{[24]}$. While another study carried out in South West Ethiopia reported that ocular trauma was found to be $(6.9 \%)^{[25] .}$

Early detection of Ophthalmological disorders via the initiation of routine Ophthalmological clinical examination as screening programs may contribute to decrease the incidence and prevalence of ocular morbidity. Further study of eye diseases at the community level is required to design proper preventive and curative strategies for eye diseases in the community.

\section{ACKNOWLEDGMENTS}

We would like to thank all the doctors and staff in the department of ophthalmology for their co-operation and help.

\section{Conflicts of interest}

There are no conflicts of interest.

\section{CONCLUSION}

It could be concluded that due to the presence of a variety of ocular disorders that affect different anatomical parts of the eye, routine clinical examination and screening programs to decrease the incidence and prevalence of ocular morbidity are required. 


\section{REFERENCES}

1. World Health Organization, Blindness and Deafness Unit \& International Agency for the Prevention of Blindness (1999): Preventing blindness in children : report of a WHO/IAPB scientific meeting, Hyderabad, India, 13-17 April.

Accessed at https://apps.who.int/iris/handle/10665/66663

2. Al-Nasser AN (1989): Screening of Eye Health Problems amongst School Children in Riyadh.Egypt J Comm Med., 5 (2): 47-53.

3. Abdou A, Nassirou B, Kadri B (2007): Prevalence and Risk Factors for Trachoma and Ocular Chlamydia Trachomatis Infection in Niger. British Journal of Ophthalmology, 91 (1): 13-17.

4. Resnikoff S, Donatella P, Daniel E, Ivo K, Ramachandra P, Gopal P, Silvio P (2004): Global Data on Visual Impairment in the Year 2002. Bulletin of the World Health Organization, 82 (11): 844 - 851.

5. Alison G, Nathan G, Emily W (2006): The New Epidemiology of Cataract."Ophthalmology Clinics of North America, 19 (4): 415 - 425.

6. El-Mekawey H, Khaled AE, Mohammad A, Amr K, Eman $M$ (2011): Epidemiology of Ocular Emergencies in the Egyptian Population: A Five-Year Retrospective Study. Clinical Ophthalmology, 5: 955-60.

7. Macky TA, Khater N, Al-Zamil MA, El Fishawy H, Soliman MM (2011): Epidemiology of Diabetic Retinopathy in Egypt: A Hospital-Based Study.Ophthalmic Research, 45 (2): 73-78.

8. Rashwan AH, El Araby AE, Nesma SM (2014): Diabetes And Hypertension As Risk Factors For Retinal Eye Diseases in Egyptian Patients, M.D. thesis, Al-Azhar University/Ophthalmology, http://thesis.mandumah.com/Record/273829

9. Sayin N, Necip K, Gökhan P (2015): Ocular Complications of Diabetes Mellitus.World Journal of Diabetes, 6 (1): 92108.

10. Oladigbolu KK, Abah ER, Chind D, Anyebe EE (2012): Pattern of Eye Diseases in a University Health Service Clinic in Northern Nigeri.Nigerian Journal of Medicine, 21 (3): 334-37.

11. WHO (2018): Blindness and vision impairment.https://www.who.int/news-room/factsheets/detail/blindness-and-visual-impairment

12. Adegbehingbe BO, Oladehinde MK, Majemgbasan TO, Onakpoya HO, and Osagiede EO (2005): Sceening Of Adolescents For Eye Diseases In Nigerian High Schools. Ghana Medical Journal, 39 (4): 138-42.

13. Felix, Agyemang M (2017): Pattern of Ocular Conditions among Patients Attending an Eye Clinic in Ghana. Optometry, 2 (01): 1-6.

14. Adeoye AO, Omotoye OJ (2007): Eye Disease in Wesley Guild Hospital, Ilesa, Nigeria.African Journal of Medicine and Medical Sciences, 36 (4): 377-80.

15. Kumah DB, Mohammed AK, Opoku Y, Adade S (2015): Prevalence of Ocular Morbidities among Basic School Children in the Kwabre East District of Ghana . International Jornal of Health \& Alied sciences, 4 (2): 111 - 114.

16. Ayanniyi AA, Feyi GA, Rashidat OA, Regina EM (2010): Challenges, Attitudes and Practices of the Spectacle Wearers in a Resource-Limited Economy. Middle East African Journal of Ophthalmology, 17 (1): 83 - 87.

17. Nwosu SN (1994): Blindness and Visual Impairment in Anambra State, Nigeria. Tropical and Geographical Medicine, 46 (6): 346 - 349.

18- Mansour AM, Kassem K, Monique C, Talal H, Abla S, Alameddine MN (1997): National Survey of Blindness and Low Vision in Lebanon. British Journal of Ophthalmology, 81 (10): 905 - 906.

19. Cohen D, Sartral M, Nounou $P$, Hamar M, Drouard ME, El Alamy A, Bendeddouche K (2000): Evaluation of moderate and severe visual impairments in patients attending an ophthalmology clinic. A prospective study of 1,172 patients. Journal francais d'ophtalmologie, 23 (5): 437-443.

20. Lamoreux E, Elaine C, Jie JW, Seang MS, Tin A (2008): Visual Impairment, Causes of Vision Loss, and Falls: The Singapore Malay Eye Study.Investigative Ophthalmology \& Visual Science, 49 (2): 528-33.

21. Mourad MS, Rafat AR, Moustafa OAM, Hamid M (2018): Prevalence of Different Eye Diseases Excluding Refractive Errors Presented at the Outpatient Clinic in Beheira Eye Hospital. The Egyptian Journal of Hospital Medicine, 71 (2): 2484-2489.

22. Scott SC, Ajaiyeoba AI (2003): Eye Diseases in General Out-Patient Clinic in Ibadan. Nigerian Journal of Medicine: Journal of the National Association of Resident Doctors of Nigeria, 12 (2): 76 - 80.

23. Munoz B, West SK, Rubin GS, Schein OD, Quigley HA, Bressler SB, Bandeen-Roche K (2000): Causes of Blindness and Visual Impairment in a Population of Older Americans: The Salisbury Eye Evaluation Study. Archives of Ophthalmology, 118 (6): 819-25.

24. Titiyal GS, Chandra P, Swati G, Vijay J (2013): Pattern of Ocular Trauma in Tertiary Care Hospital of Kumaon Region , Uttarakhand. J Indian Acad Forensic Med., 35 (2): 116-19.

25. Asaminew T, Yeshigeta G, Fessehaye A (2009):A 2-Year Review Of Ocular Trauma In Jimma University Specialized Hospital. Ethiop J Health Sci., 19 (2): 67-74. 